Article

\title{
Cultivation of hMSCs in Human Plasma Prevents the Cytotoxic and Genotoxic Potential of ZnO-NP In Vitro
}

\author{
Agmal Scherzad ${ }^{1, *}$, Till Meyer ${ }^{1}{ }^{(\mathbb{D}, \text { Pascal Ickrath }}{ }^{1} \mathbb{1}$, Thomas Eckhart Gehrke ${ }^{1}$, \\ Maximillian Bregenzer ${ }^{1}$, Rudolf Hagen ${ }^{1}$, Sofia Dembski ${ }^{2}$ and Stephan Hackenberg ${ }^{1}$ (ID \\ 1 Department of Otorhinolaryngology, Plastic, Aesthetic and Reconstructive Head and Neck Surgery, \\ Julius Maximilian University of Wuerzburg, 97080 Würzburg, Germany; meyer_t2@ukw.de (T.M.); \\ Ickrath_p@ukw.de (P.I.); Gehrke_T@ukw.de (T.E.G.); Bregenzer_M@ukw.de (M.B.); Hagen_R@ukw.de (R.H.); \\ Hackenberg_S@ukw.de (S.H.) \\ 2 Fraunhofer Institute for Silicate Research, ISC, Neunerplatz 2, 97082 Würzburg, Germany; \\ sofia.dembski@isc.fraunhofer.de \\ * Correspondence: Scherzad_A@ukw.de
}

Received: 23 October 2019; Accepted: 16 November 2019; Published: 20 November 2019

check for updates

\begin{abstract}
Zinc oxide nanoparticles (ZnO-NPs) are commonly used for industrial applications. Consequently, there is increasing exposure of humans to them. The in vitro analysis of cytotoxicity and genotoxicity is commonly performed under standard cell culture conditions. Thus, the question arises of how the results of genotoxicity and cytotoxicity experiments would alter if human plasma was used instead of cell culture medium containing of fetal calf serum (FCS). Human mesenchymal stem cells (hMSCs) were cultured in human plasma and exposed to ZnO-NPs. A cultivation in expansion medium made of DMEM consisting 10\% FCS (DMEM-EM) served as control. Genotoxic and cytotoxic effects were evaluated with the comet and MTT assay, respectively. hMSC differentiation capacity and $\mathrm{ZnO}-\mathrm{NP}$ disposition were evaluated by histology and transmission electron microscopy (TEM). The protein concentration and the amount of soluble $\mathrm{Zn}^{2+}$ were measured. The cultivation of hMSCs in plasma leads to an attenuation of genotoxic and cytotoxic effects of ZnO-NPs compared to control. The differentiation capacity of hMSCs was not altered. The TEM showed ZnO-NP persistence in cytoplasm in both groups. The concentrations of protein and $\mathrm{Zn}^{2+}$ were higher in plasma than in DMEM-EM. In conclusion, the cultivation of hMSCs in plasma compared to DMEM-EM leads to an attenuation of cytotoxicity and genotoxicity in vitro.
\end{abstract}

Keywords: ZnO-NP; mesenchymal stem cells; genotoxicity; cytotoxicity; human plasma

\section{Introduction}

The use of nanotechnology has been increasing in industry, biomedicine and research during the last years. According to the conventional definition, nanoparticles (NPs) range from $1 \mathrm{~nm}$ to $100 \mathrm{~nm}$. However, this definition cannot be exhaustive. Therefore, several particle systems with diameters larger than $100 \mathrm{~nm}$ are commonly also defined as NPs [1]. Compared to larger particles of the same composition, these particles exhibit completely altered mechanical, optical, electrical, magnetic and catalytic properties. Moreover, their size has an effect on the bioactivity as well [2]. Many different NPs, e.g., silver, zinc, gold and titanium are freely available for consumers. Especially for industrial applications, zinc oxide $(\mathrm{ZnO}) \mathrm{NPs}$ are among the most frequently used nanomaterials. Thus, the amount of synthetically produced ZnO-NPs is continuously increasing, since they are applied as catalysts in the chemical branch, and are a standard ingredient in pharmaceutical and cosmetic products. Furthermore, due to its favorable semi-conductor properties, numerous electronic components contain $\mathrm{ZnO}$ [3]. Consequently, there is increasing human exposure to ZnO-NPs. Common routes of uptake 
into the human organism are the digestive tract, the skin and the respiratory tract. The exposure route via inhalation may affect respiratory and alveolar cells by causing toxic, genotoxic or inflammatory effects [4]. In particular, the incorporation of superfine structures by inhalation has adverse local and systemic side effects, such as increased risk of cardiovascular disorders [5]. A major subject of concern about the increasing usage of $\mathrm{ZnO}-\mathrm{NPs}$ in consumer goods is that safety aspects remain uncertain, since data on genotoxic and cytotoxic properties of $\mathrm{ZnO}-\mathrm{NPs}$ are limited. There is an imbalance between the particles' dosages for the inductions of genotoxicity and cytotoxicity [6]. Chemically stable NPs do not show significant toxicity. In contrast to that, NPs which can be oxidized, reduced or dissolved are often cytotoxic and genotoxic to cellular organisms [7]. Concerning this topic, we were able to show a correlation between ion levels and genotoxic reactions of $\mathrm{ZnO}-\mathrm{NPs}$ in vitro [8]. As a fact, the in vitro results concerning genotoxicity and cytotoxicity do not reflect the in vivo situation precisely. Nevertheless, in vitro results of toxic substances may represent trends to potentially harmful events in the in vivo setting. To our opinion, diverse settings for the analysis of nanotoxicity have to be applied and evaluated. The in vitro analysis of cytotoxicity and genotoxicity of NPs is commonly performed under standard cell culture conditions. The media of these systems are routinely supplemented with animal serum like 10\% fetal calf serum (FCS). Hsiao and Huang published a paper in 2013 on the impact of serum on cytotoxicity of ZnO-NPs. They tested several concentrations of FCS-supplemented cell culture medium and found that there was a correlation between cytotoxicity and inflammation endpoints between the groups. They recommended using serum-based medium for the assessment of the cytotoxicity of NP. However, there is a lack of experiments using pure human serum instead of FCS-supplemented cell culture medium [9]. The protein content, which is crucially influencing toxicity of NPs, is different in the in vivo setting. Thus, the question arises of how the results of genotoxicity and cytotoxicity assays would alter if $100 \%$ of human plasma was used instead of cell culture medium containing of $10 \%$ FCS. Therefore, the current study aimed to investigate differences in cytotoxic and genotoxic effects of ZnO-NPs in primary human cells. Our group favors the use of human mesenchymal stem cells (hMSCs) for nanotoxicological evaluations, since they are a very stable primary cell system with a high regenerative ability after toxic events and the possibility to perform long-term cultivation.

\section{Materials and Methods}

\subsection{Media Preparation for Cell Culture}

\subsubsection{Plasma Isolation from Human Peripheral Blood}

In this study, the effects of ZnO-NPs on hMSCs were analyzed under the presence of standard cell culture medium consisting of Dulbecco's modified Eagle's medium (DMEM) with 10\% FCS (Linaris, Wertheim-Bettingen, Germany), $1 \%$ penicillin and streptomycin (Sigma-Aldrich, Schnelldorf, Germany) (DMEM-EM) versus pure human plasma from peripheral blood. In order to separate the plasma, $30 \mathrm{~mL}$ of venous blood was collected from a voluntary healthy donor. A ficoll density gradient centrifugation was applied (30 min, 1300 rpm without brake, density, 1077 g/mL; Biochrom AG, Berlin, Germany). After centrifugation, the plasma phase was collected.

All following experiments were performed with primary cell-free human plasma. DMEM-EM served as control.

\subsubsection{Isolation and Culture of Human Mesenchymal Stem Cells}

hMSCs were harvested from three voluntary patients who underwent liposuction for aesthetic purposes. Studies were authorized by the Ethics Council of the Medical Department of the Julius-Maximilians-University Würzburg (grant number 91/19) and informed consent was obtained from all individuals included in the study. The isolation process was carried out as described previously [10]. Liposuction material was washed with phosphate-buffered saline (PBS; Roche 
Diagnostics GmbH, Mannheim, Germany) plus 1\% penicillin/streptomycin, and digested with collagenase P (Roche Diagnostics $\mathrm{GmbH}$ ). The separation of the stromal cell fraction from the adipose cells was achieved by centrifugation. Next, the removal of erythrocytes in the residual cell pellet was achieved by the erythrocyte lysis buffer (154 mM ammonium chloride, $10 \mathrm{mM}$ potassium bicarbonate and $0.1 \mathrm{mM}$ ethylenediaminetetraacetic acid (EDTA)). After several centrifugation and washing steps, cells were resuspended in DMEM-EM and plated in culture flasks, which were maintained at $37^{\circ} \mathrm{C}$ in a moistened atmosphere with $5 \% \mathrm{CO}_{2}$. Medium was changed every third day during expansion.

Flow cytometric analysis (Becton Dickinson (BD) FACSCanto TM; BD Bioscience, Bedford, MA, USA) was performed in order to determine the hMSC-specific cell surface marker expression. The following antibodies were used: anti-cluster of differentiation (CD)34 (phycoerythrin (PE), number 550761), anti-CD44 (fluorescein isothiocyanate (FITC), number 555478), anti-CD45 (FITC, number 555482), antiCD73 (PE, number 550257), anti-CD90 (allophycocyanin (APC), number 559869) and anti-CD105 (FITC, numbers 555690 and 555988). All antibodies were purchased from BD. In addition, osteogenic and adipogenic differentiation was performed as described before [11]. Osteogenic differentiation was induced by cultivation of hMSCs with DMEM-EM plus $10^{-7} \mathrm{M}$ dexamethasone, $10^{-3} \mathrm{M} \beta$-glycerophosphate and 2-4 M ascorbate-2-phosphate (all from Sigma-Aldrich). Adipogenic differentiation was achieved after cultivation of hMSCs in DMEM-EM with $10^{-7} \mathrm{M}$ dexamethasone and $10^{-9} \mathrm{~g} / \mathrm{mL}$ recombinant human insulin (all from Sigma-Aldrich). Von Kossa and Oil Red O-staining were used to confirm osteogenic and adipogenic differentiation, respectively.

\subsection{Chemicals}

ZnO-NPs ( $<20 \mathrm{~nm}$ ) were purchased from mkNANO (Mississauga, ON, Canada). An amount of $5 \mathrm{mg}$ of the particles was added to $870 \mu \mathrm{L}$ sterilized distilled water. A sonication (Bandelin, Sonopuls HD 60, Berlin, Germany) of the stock suspension was performed for $60 \mathrm{~s}$ at an energy level of $4.2 \times 10^{5} \mathrm{~kJ} / \mathrm{m}^{3}$. In order to achieve a high degree of dispersion, a continuous mode was used according to the protocol of Bihari et al. [12]. The stabilization of the dispersion was achieved by adding $30 \mu \mathrm{L}$ of $1.5 \mathrm{mg} / \mathrm{mL}$ bovine serum albumin (BSA). At the end, $1 \times 10^{2} \mu \mathrm{L}$ of $10 \times$ concentrated PBS was applied in order to achieve a physiological salt concentration at $\mathrm{pH}$ 7.4. The main solution was rarefied with either DMEM-EM or plasma.

\subsection{Characterization of Nanoparticles}

Transmission electron microscopy (TEM) was used to determine the structure and dimensions of nanoparticles in the mass dispersion. The TEM specimens were generated by drop coating of the main suspension on carbon-coated copper grids. Several aspects of the particle, namely, shape, size, size distribution and tendency of aggregation, were characterized. A Zeiss EM 900 transmission electron microscope (Carl Zeiss, Oberkochen, Germany) was used in the Department of Electron Microscopy at the Biocenter of the University of Würzburg. The zeta potential of the NPs in the media (DMEM-EM and human plasma) at pH 7.4 was investigated by a ZetaSizer 3000HSA (Malvern Instruments Ltd.) at the Fraunhofer Institute for Silicate Research ISC in Wuerzburg. Dissolved $\mathrm{Zn}^{2+}$ ions in the culture medium (DMEM-EM and human plasma) were determined by atomic absorption spectrometry (SpectraAA 55 B, Varian GmbH, Darmstadt, Germany).

\section{Cell Treatment}

After sonication of the particles as mention above, cell treatment started immediately. $500 \mu \mathrm{L}$ of diluted nanoparticle dilution were used at final concentrations of $0,10,15,20$ and $50 \mu \mathrm{g} / \mathrm{mL}$ per well. In the first arm, NP were diluted in DMEM-EM whereas in the second arm, dilution was performed with plasma. For genotoxicity testing, DMEM-EM served as the negative control, and directly alkylating methyl methane sulphonate (MMS, Sigma-Aldrich) as the positive control. hMSCs were exposed to $\mathrm{ZnO}-\mathrm{NPs}$ for $24 \mathrm{~h}$ at $37^{\circ} \mathrm{C}$ in a humidified incubator with $5 \% \mathrm{CO}_{2}$. 


\subsection{Cell Preparation for TEM}

After an exposure of $24 \mathrm{~h}$, cell aggregates were obtained in order to analyze the ultrastructural and the intracellular distribution of nanoparticle. A fixation was achieved as previously described with a fresh solution of $0.1 \mathrm{M}$ sodium cacodylate containing $2.5 \%$ glutaraldehyde and $2 \%$ formaldehyde. This procedure was followed by a $2 \mathrm{~h}$ fixation at $4{ }^{\circ} \mathrm{C}$ with $2 \%$ osmium tetroxide in $50 \mathrm{mM}$ sodium cacodylate ( $\mathrm{pH} 7.2$ ). Then, an overnight incubation with $0.5 \%$ aqueous uranyl acetate was performed. After dehydration of the specimens, embedding in Epon 812 and sectioning into ultrathin slices was performed. The slides were analyzed with an EM900 electron microscope (Carl Zeiss) and photographic negatives were digitalized by scanning $[13,14]$.

\subsection{Measurement of Cell Death}

ZnO-NPs cytotoxicity was assessed using the MTT [3-(4,5-dimethylthiazol-2-yl)-2,5-diphenyl tetrazolium bromide] (Sigma Aldrich) assay. hMSCs were treated with ZnO-NPs at following concentrations: $0,10,15$ and $20 \mu \mathrm{g} / \mathrm{mL}$. After $24 \mathrm{~h}$ of treatment, the medium was discarded, and the cells rinsed with PBS. MTT solution was administered at a concentration of $1 \mathrm{mg} / \mathrm{mL}$ for $5 \mathrm{~h}$ at $37^{\circ} \mathrm{C}$ with $5 \% \mathrm{CO}_{2}$. Afterwards, the MTT was removed and $100 \mu \mathrm{L}$ Isopropanol was applied for $1 \mathrm{~h}$. Absorption intensities were determined with a microplate photometer at a wavelength of $570 \mathrm{~nm}$. A $200 \mu \mathrm{M}$ solution of tert-butylhydroperoxide (t-BHO) was used as a positive control.

\subsection{Alkaline Single-Cell Microgel Electrophoresis (Comet) Assay}

The alkaline comet assay was used to identify DNA strand breaks and alkali labile and incomplete excision repair sites in single cells. The slides were prepared as described before [8,15]. In order to quantify the DNA damage induced, the percentage of DNA in the tail was determined in the present study. MMS served as positive control. The COMET 5.5 imaging system (Kinetic Imaging, Liverpool, UK) was applied for the analysis of DNA fragmentation. The parameter tail DNA was analyzed and used for statistical evaluation.

\subsection{Measurement of Protein and $\mathrm{Zn}^{2+}$ Concentrations in Plasma and DMEM-EM}

$\mathrm{Zn}^{2+}$ ions in the culture medium were determined by atomic absorption spectrometry (SpectraAA $55 \mathrm{~B}$, Varian $\mathrm{GmbH}$, Darmstadt, Germany) in order to measure the concentration of zinc ions in plasma and DMEM-EM. The protein concentration was measured photometrically at $280 \mathrm{~nm}$.

\subsection{Statistical Analysis}

The statistical evaluation of the data was done with GraphPad Prism, version 6. To determine the differences a one-way ANOVA was performed, followed by a Dunnett's post-hoc multiple comparison test. A $p$-value less than 0.05 was considered statistically significant and marked with *

\section{Results}

\subsection{Isolation and Characterization of MSC}

hMSCs showed the typical fibroblast like morphology. The cells were plastic adherent. The flow cytometric analysis showed the presence of surface markers CD105, CD90 and CD44, and the absence of CD34 (data not shown). A cultivation of hMSCs in plasma was possible. The cells differentiated into osteogenic and adipogenic lineages, which was verified by the Von Kossa and Oil Red O staining (Figure 1). 


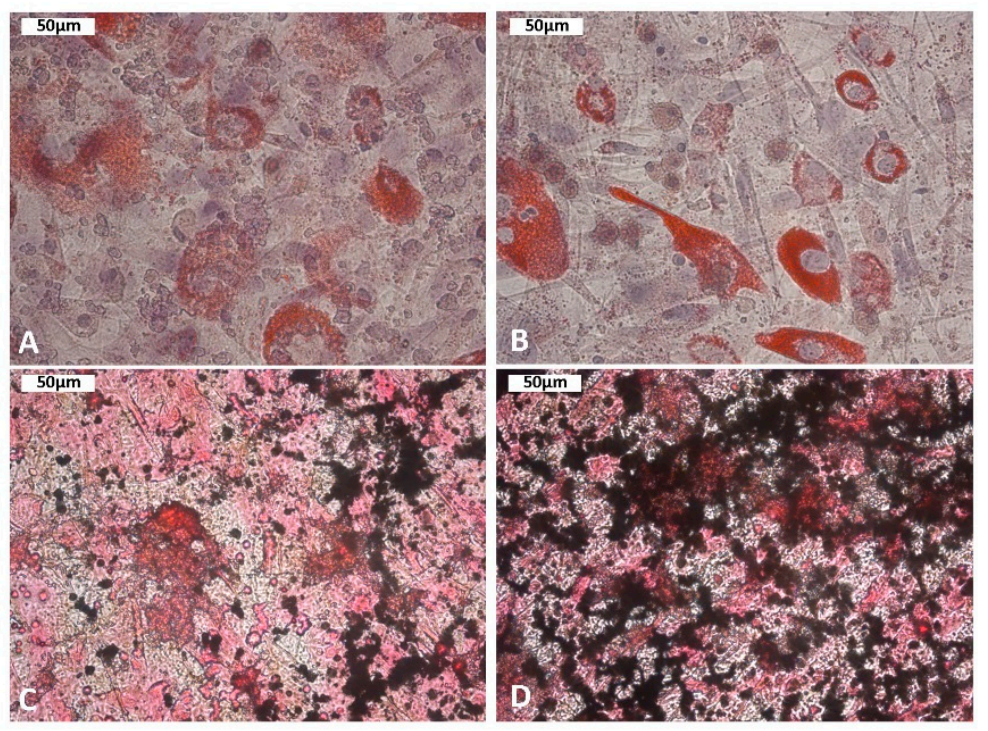

Figure 1. Proof of multipotency. Human mesenchymal stem cells' (hMSCs) differentiation towards osteogenic and adipogenic lineages was compared with those cultivated in DMEM-EM (A,C) and plasma (B,D). The adipogenic differentiation was confirmed with the Oil Red O staining $(\mathbf{A}, \mathbf{B})$, showing lipid droplets as red spots. The osteogenic differentiation was confirmed with the Van Kossa staining (C,D), showing calcium deposits as dark dots.

\subsection{Analysis of MSC Proliferation}

After cultivation of hMSCs in plasma, each day, the cells were counted. The experiment ended at day 3. In plasma, hMSCs demonstrated a significant increase in proliferation compared to cultivation in DMEM-EM. Figure 2 shows that hMSCs proliferated almost 2.3-fold faster in plasma compared to DMEM-EM.

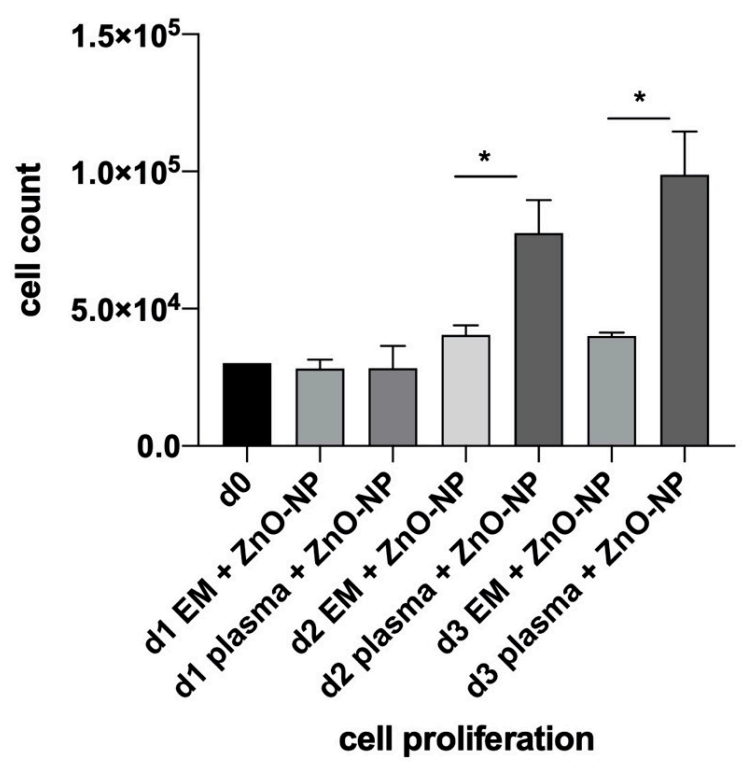

Figure 2. Cell proliferation analysis. hMSC proliferation was evaluated. The significance analysis was assessed as described above. Each day the cells were counted. hMSCs in plasma showed a significant enhancement of proliferation compared to cultivation in DMEM-EM at day 2 and 3. * indicates the statically significant changes. 


\subsection{Particle Characterization}

ZnO-NPs were shaped like spheres and rods with a mean diameter of $34 \mathrm{~nm}$ according to the manufacturer's declaration. The dispersion was analyzed by DLS. Using cell culture medium, the mean agglomeration size was $48 \mathrm{~nm}$ with a second population of large agglomerates measuring a diameter of more than $5000 \mathrm{~nm}$. The size of ZnO NP agglomerates in human plasma was $59 \mathrm{~nm}$. High variations in agglomerate size were seen in both groups. Single $\mathrm{ZnO}-\mathrm{NPs}$ were visible by TEM within the cytoplasm sparing the nucleus in both groups, DMEM-EM and plasma. In the DMEM-EM group, larger counts of particles (4.2 single particle per slice) were seen compared to the plasma group (1.6 single particles per slice). The zeta-potential of ZnO-NPs was $-11.2 \mathrm{mV}$ (Figures 3 and 4).
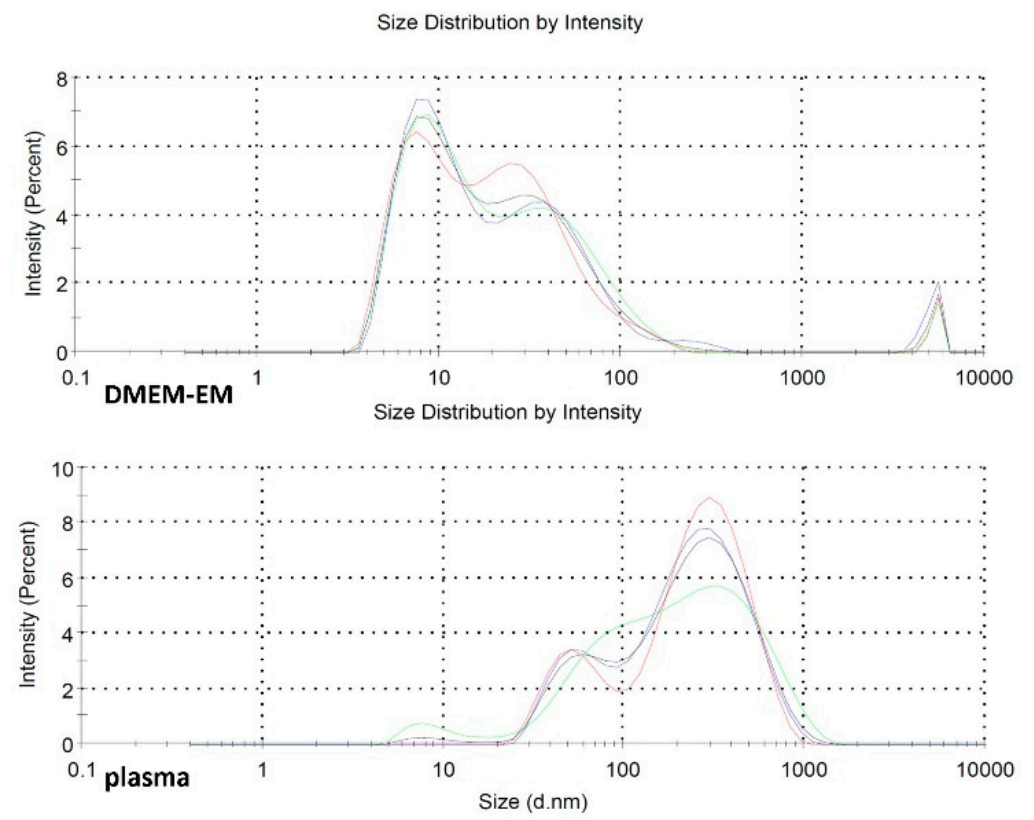

Figure 3. ZnO-nanoparticle (NP) characterization. The dispersion was analyzed by DLS. The sizes of ZnO-NPs in plasma and DMEM-EM were evaluated. In both groups, high variations in agglomerate size could be detected.
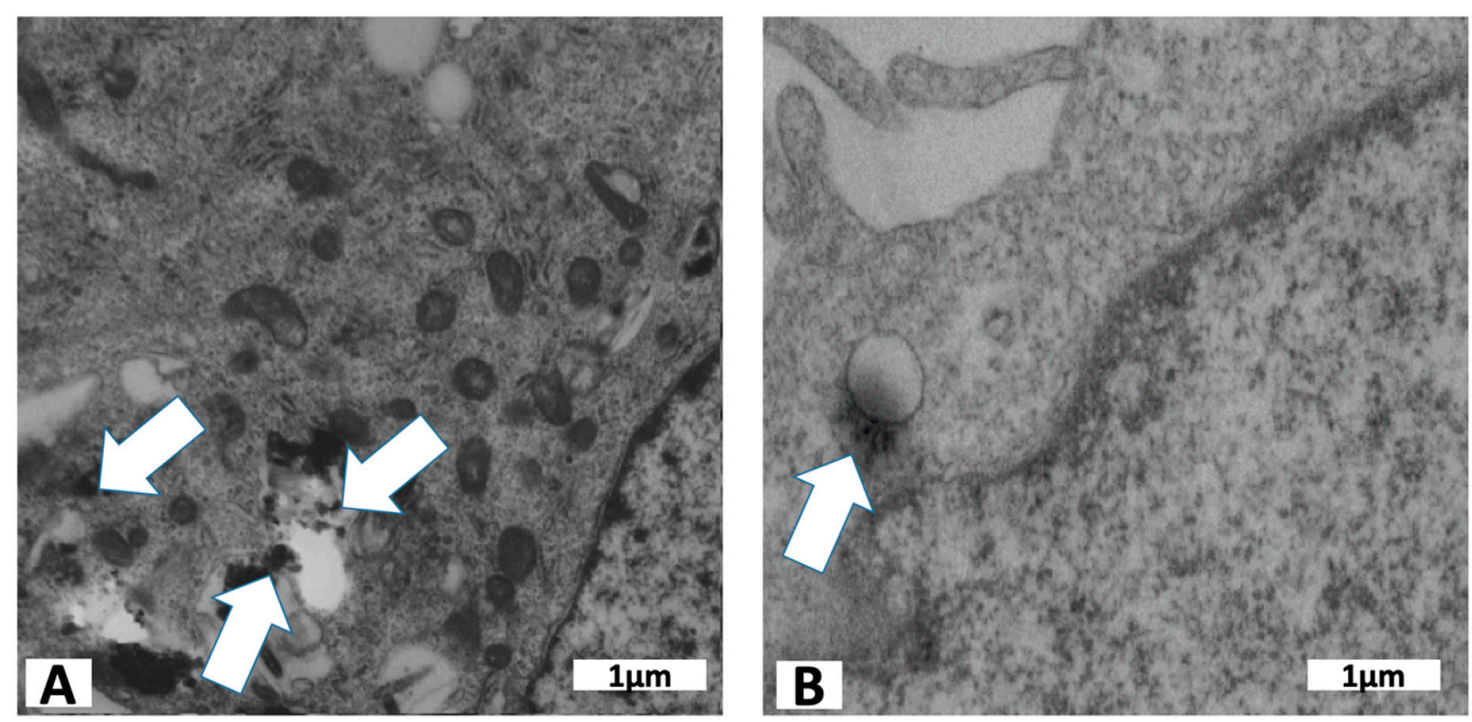

Figure 4. ZnO-NP disposition. TEM analysis of hMSCs cultivated with DMEM-EM (A) and plasma (B) after $\mathrm{ZnO}-\mathrm{NP}$ exposure. In both pictures, $\mathrm{ZnO}-\mathrm{NP}$ can be detected within the cytoplasm. 


\subsection{Cell Viability}

The MTT assay was performed to evaluate the cell viability of hMSCs after exposure to ZnO-NPs. The MTT test revealed a significant decrease in hMSC viability cultivated in DMEM-EM at a ZnO-NP level of $20 \mu \mathrm{g} / \mathrm{mL}$ compared to the control with a $p$-value $<0.05$. After the administration of ZnO-NPs in plasma at concentrations of $20 \mu \mathrm{g} / \mathrm{mL}$ and $25 \mu \mathrm{g} / \mathrm{mL}$, no reduction of cell viability could be detected. A significant decrease of cell viability was measured after adding of MMS (Figures 5 and 6).

\section{DMEM-EM}

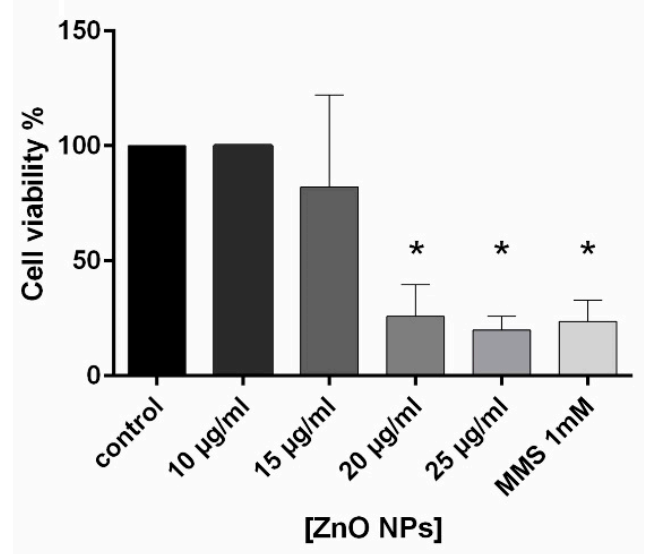

Figure 5. Cytotoxicity. In the MTT assay, the cytotoxic effects of ZnO-NPs in hMSCs cultured in DMEM-EM were analyzed. Statistical analysis was performed as described above. The test showed a significant reduction of hMSC viability at a ZnO-NP concentration of $20 \mu \mathrm{g} / \mathrm{mL}$. * indicates the statically significant changes.

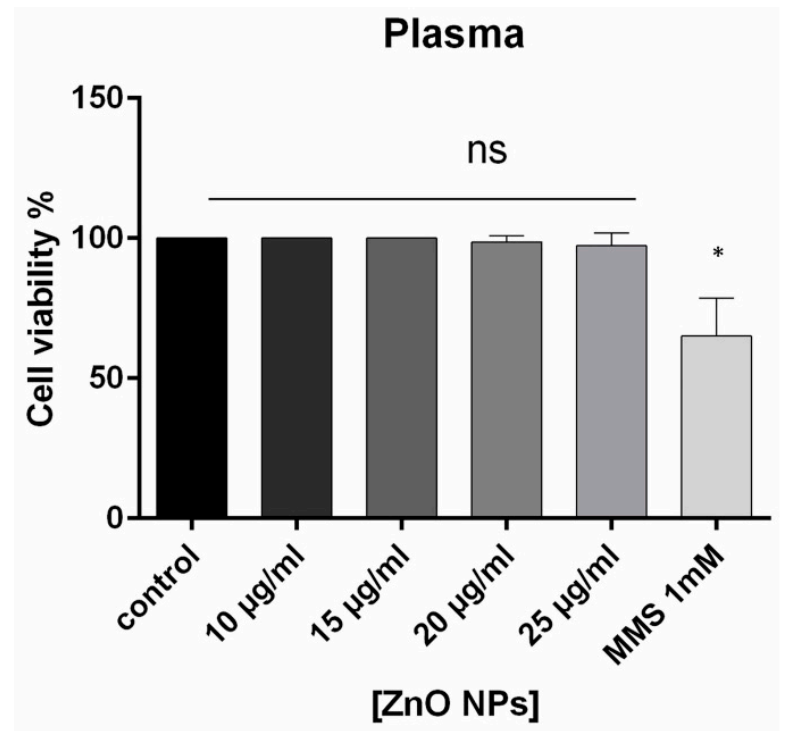

Figure 6. Cytotoxicity. The MTT assay was performed to analyze the cytotoxic effects of ZnO-NP in hMSCs cultivated in plasma. No attenuation of cell viability could not be observed after exposure to $\mathrm{ZnO}-\mathrm{NPs}$ at the concentrations of $20 \mu \mathrm{g} / \mathrm{mL}$ as well as $25 \mu \mathrm{g} / \mathrm{mL}$. Statistical analysis was performed as described above. A significant attenuation of cell viability was measured after adding of MMS. * indicates the statically significant changes.

\subsection{Genotoxicity}

The increase in the proportion of DNA in the tail compared to the entire content of DNA is an indicator of genotoxic potential. Since cytotoxic effects could be detected at the concentration of $20 \mu \mathrm{g} / \mathrm{mL}$, genotoxic effects were evaluated at $10 \mu \mathrm{g} / \mathrm{mL}$ and $15 \mu \mathrm{g} / \mathrm{mL}$. hMSCs cultivated in DMEM-EM 
showed a significant enhancement of DNA damage at $15 \mu \mathrm{g} / \mathrm{mL}$ ( $p$-value $<0.05$ ). hMSC cultivated in plasma did not show any signs of genotoxic events at those concentrations. After adding MMS as a positive control, significant alteration of DNA damage was detected (Figure 7).

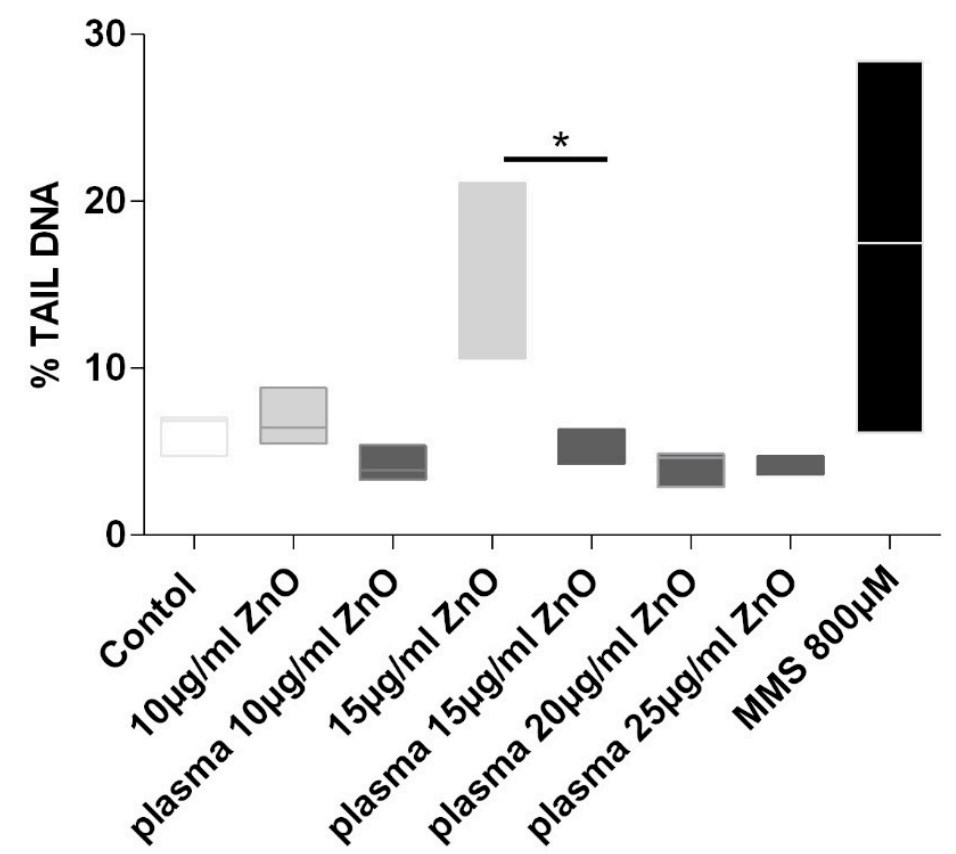

Figure 7. The comet assay was used in order to evaluate genotoxic events after hMSCs' exposure to ZnO-NPs. hMSCs cultivated in DMEM-EM showed a significant enhancement of DNA damage at $15 \mu \mathrm{g} / \mathrm{mL}$ ( $p$-value < 0.05) compared to the cultivation in plasma. Statistical analysis was performed as described above. MMS served as a positive control. * indicates the statically significant changes.

\subsection{Measurement of Protein and $\mathrm{Zn}^{2+}$ Concentration in Plasma and DMEM-EM}

After dilution of the stock suspension, either with DMEM-EM or plasma at different concentrations, the amounts of soluble zinc ions were measured at different concentrations. The amount of soluble $\mathrm{Z}^{2+}$ ions increased steadily with the concentration of $\mathrm{ZnO}-\mathrm{NPs}$. The concentrations of soluble $\mathrm{Zn}^{2+}$ ions were higher in plasma compared to DMEM-EM (Table 1). Furthermore, the total protein concentrations in DMEM-EM and plasma were investigated as well. Plasma showed total protein concentrations of $54.4 \mu \mathrm{g} / \mu \mathrm{L}$ and DMEM-EM $10.6 \mu \mathrm{g} / \mu \mathrm{L}$, respectively.

Table 1. The amount of soluble zinc ions in DMEM-EM and plasma independent of the different $\mathrm{ZnO}-\mathrm{NP}$ concentrations. Furthermore, the protein concentration is pictured in the table as well.

\begin{tabular}{ccc}
\hline \multicolumn{3}{c}{ Protein and $\mathbf{Z n}^{2+}$ Concentration in Plasma and DMEM-EM } \\
\hline $\mathrm{ZnO}(\mu \mathrm{g} / \mathrm{mL})$ & DMEM-EM ng/mL & Plasma $\mathrm{ng} / \mathrm{mL}$ \\
0 & 0 & 9.9 \\
10 & 121.9 & 122.2 \\
15 & 130.7 & 170.4 \\
20 & 150.5 & 242.4 \\
25 & 171.1 & 396.5 \\
Protein $\mu \mathrm{g} / \mu \mathrm{L}$ & DMEM-EM & Plasma \\
& 10.6 & 54.4 \\
\hline
\end{tabular}

\section{Discussion}

In the current study, cultivation of $\mathrm{ZnO} \mathrm{NP}$ under standard conditions was compared to cell cultivation with human plasma. The cell proliferation was checked by cell counting. Cells in the plasma group showed a significant increase in proliferation compared to cultivation with DMEM-EM. 
The cell count was not performed as a toxicological evaluation, but to show the significant difference between the two media types with respect to cell proliferation. We demonstrated significant differences in genotoxicity and cytotoxicity. While standard cultivation with DMEM-EM showed dose-dependent DNA damage and toxicity at $15 \mu \mathrm{g} / \mathrm{mL}$ of $\mathrm{ZnO}-\mathrm{NPs}$, no such effects were found in the cultivation of cells with plasma and exposure to $25 \mu \mathrm{g} / \mathrm{mL}$ of ZnO-NPs. Interestingly, NPs were frequently seen intracellularly in both the DMEM-EM group and in the plasma group. However, in the plasma group a lower quantity of NPs was seen. Dayem et al. stated that exocytosis or the release of NPs occurs through vesicle-dependent release, non-vesicle-dependent release and lysosomal secretion [16]. It is obvious that there must be a correlation between toxicity of particles and their intracellular retention. A possible explanation of the differences of intracellular NP quantities could be a higher release of particles from the cells in the plasma group. In the plasma group, the concentration of zinc ions was more than double. The question arises as to whether the NPs were not taken up by the cells or were internalized but quickly released again. Since TEM was only performed at one specific time point, this question could not be answered through our investigation. However, it seems to be more likely that the major difference is due to NPs' uptake. Consequently, it has to be clarified why NPs are taken up less by the cells in the plasma group. Differences seen in DLS could explain our findings. Particle agglomerates were larger in the plasma group, so cellular uptake will consequently be decreased. As a limitation to this study, we have to state, that size distribution has a wide range in both groups. Therefore, a mixture of different sized particle eczema rates cannot be considered a homogeneous sample. However, particles pretreated according to the standard protocol may show such inhomogeneous agglomeration. For adequate toxicological evaluations, a high grade of dispersion has to be intended.

There are some studies discussing the mechanisms of endo and exocytosis of NP into cells. According to Rejman et al., various endocytosis pathways can be differentiated, including phagocytosis, macroproteinocytosis, clathrin-mediated endocytosis and non-clathrin-mediated endocytosis, the latter with internalization via caveolae [17]. Furthermore, in a previous study the authors hinted the importance of size in particle entry $[17,18]$. Win and colleagues confirmed this hypothesis. They evaluated the size-dependent particle endocytosis and found that gold NPs with the size $<50 \mathrm{~nm}$ showed the highest cellular uptake [19]. Furthermore, the shape of the particles play an important role as well. In a study performed by Hsiao it was shown that ZnO-NPs had a higher toxicity than bulk $\mathrm{ZnO}$ in human lung epithelial cells [20]. Furthermore, the rod-shaped particles were much more toxic than the spherical ones, suggesting that both the size and shape of the NPs affect their cytotoxicity [20]. One possible cause could be that rod-shaped particles might have an enhanced contact with the cell membrane due to their configuration and this may lead to an enhanced particle incorporation into the cytoplasm. Besides the size and shape, the surface charge and chemistry of the NPs may influence cellular uptake, too. It was shown that positively charged NPs had a higher bioavailability in vitro and in vivo [21]. The uptake of the positively-charged particles is also enhanced compared to their negative counterparts [22]. Massignani could show that cellular uptake kinetics are controlled by surface chemical properties [23]. In the present study, there was no difference between the two groups in terms of physical and chemical properties. Thus, the corona and agglomeration of NPs may mainly influence the cellular uptake compared to the other parameters discussed above. Surely, the protein concentration in the cell culture fluid plays an important role in this context. In the plasma group, the concentration of the protein was understandably higher than the control group.

In terms of endocytosis, there are many publications, whereas few studies are found in the literature dealing with exocytosis. However, this topic is very important since with the exocytosis the intracellular NPs concentration is regulated. In a previous study, we showed that NPs persisted in mesenchymal stem cells for at least 3 weeks, without being discharged [24]. Definitely, the assertion of this finding has its limitations, since the in vitro system is not comparable to the mechanism in vivo. Nevertheless, the question arises about the fate of the intracellular NPs. In our opinion, the size of the single particles and the agglomerations might play important roles, since small NPs have the ability to leave the cell much easier compared to the bigger ones. Chitrani et al. showed that transferrin-coated 
gold nanoparticles (Au NPs) with sizes of $14 \mathrm{~nm}$ were discharged much better than NPs with diameters of $50 \mathrm{~nm}$ and $74 \mathrm{~nm}$ [25]. In terms of exocytosis, the coating is a relevant factor, too. To substantiate this statement, Bartczak and colleagues could show a significant affection of NPs exocytosis by altering their surface coating [26]. Furthermore, in an in vitro system the exocytosis also depends on the amount of extracellular NPs [27]. The authors are aware that the use of plasma alone cannot be representative based on the blood compositions. However, the results of the present study are distinctly different from the standards cultivation in DMEM. Therefore, there is a need for further studies evaluating toxicological aspects of NPs in human cells cultured with human plasma. Of course, human-particle interactions take not only place in the plasma but also in the cells of the aerodigestive tract, and on all bodily surfaces. This might be a relevant cause for the divergent results between in vitro and in vivo systems. To clarify and emphasize, our study does not put toxicological investigations of in vitro system with medium into question. Much more, these systems are tremendously necessary in order to clarify cellular mechanisms after NP contact.

Author Contributions: Conceptualization, A.S. and S.H.; methodology, T.M., P.I., M.B. and S.D.; software, T.M.; validation, T.E.G., M.B. and S.H.; formal analysis, T.E.G., A.S.; investigation, A.S., S.D. and S.H.; resources, S.H.; data curation, A.S. and S.H.; writing-A.S. and S.H.; writing—review and editing, R.H., S.H.; visualization, A.S., P.I. and S.H.; supervision, R.H., A.S. and S.H.; project administration, T.M.

Funding: This research received no external funding.

Conflicts of Interest: The authors declare no conflict of interest.

\section{References}

1. Englert, B.C. Nanomaterials and the environment: Uses, methods and measurement. J. Environ. Monit. JEM 2007, 9, 1154-1161. [CrossRef] [PubMed]

2. Shi, H.B.; Magaye, R.; Castranova, V.; Zhao, J.S. Titanium dioxide nanoparticles: A review of current toxicological data. Part. Fibre Toxicol. 2013, 10, 15. [CrossRef] [PubMed]

3. Klingshirn, C. ZnO: Material, physics and applications. Chemphyschem 2007, 8, 782-803. [CrossRef] [PubMed]

4. Osmond, M.J.; Mccall, M.J. Zinc oxide nanoparticles in modern sunscreens: An analysis of potential exposure and hazard. Nanotoxicology 2010, 4, 15-41. [CrossRef]

5. Vermylen, J.; Nemmar, A.; Nemery, B.; Hoylaerts, M.F. Ambient air pollution and acute myocardial infarction. J. Thromb. Haemost. JTH 2005, 3, 1955-1961. [CrossRef]

6. Singh, N.; Manshian, B.; Jenkins, G.J.; Griffiths, S.M.; Williams, P.M.; Maffeis, T.G.; Wright, C.J.; Doak, S.H. NanoGenotoxicology: The DNA damaging potential of engineered nanomaterials. Biomaterials 2009, 30, 3891-3914. [CrossRef]

7. Auffan, M.; Rose, J.; Wiesner, M.R.; Bottero, J.Y. Chemical stability of metallic nanoparticles: A parameter controlling their potential cellular toxicity in vitro. Environ. Pollut. 2009, 157, 1127-1133. [CrossRef]

8. Hackenberg, S.; Scherzed, A.; Technau, A.; Kessler, M.; Froelich, K.; Ginzkey, C.; Koehler, C.; Burghartz, M.; Hagen, R.; Kleinsasser, N. Cytotoxic, genotoxic and pro-inflammatory effects of zinc oxide nanoparticles in human nasal mucosa cells in vitro. Toxicol. In Vitro 2011, 25, 657-663. [CrossRef]

9. Hsiao, I.L.; Huang, Y.J. Effects of serum on cytotoxicity of nano- and micro-sized ZnO particles. J. Nanopart Res. 2013, 15, 1829. [CrossRef]

10. Frolich, K.; Scherzed, A.; Mlynski, R.; Technau, A.; Hagen, R.; Kleinsasser, N.; Radeloff, A. Multipotent stromal cells for autologous cell therapy approaches in the guinea pig model. ORL J. Oto Rhino Laryngol. Its Relat. Spec. 2011, 73, 9-16. [CrossRef]

11. Scherzad, A.; Hackenberg, S.; Froelich, K.; Rak, K.; Hagen, R.; Taeger, J.; Bregenzer, M.; Kleinsasser, N. Chronic exposure of low dose salinomycin inhibits MSC migration capability in vitro. Biomed. Rep. 2016, 4 , 325-330. [CrossRef] [PubMed]

12. Bihari, P.; Vippola, M.; Schultes, S.; Praetner, M.; Khandoga, A.G.; Reichel, C.A.; Coester, C.; Tuomi, T.; Rehberg, M.; Krombach, F. Optimized dispersion of nanoparticles for biological in vitro and in vivo studies. Part. Fibre Toxicol. 2008, 5, 14. [CrossRef] [PubMed] 
13. Gehrke, T.; Scherzad, A.; Ickrath, P.; Schendzielorz, P.; Hagen, R.; Kleinsasser, N.; Hackenberg, S. Zinc oxide nanoparticles antagonize the effect of Cetuximab on head and neck squamous cell carcinoma in vitro. Cancer Biol. Ther. 2017, 18, 513-518. [CrossRef] [PubMed]

14. Ickrath, P.; Wagner, M.; Scherzad, A.; Gehrke, T.; Burghartz, M.; Hagen, R.; Radeloff, K.; Kleinsasser, N.; Hackenberg, S. Time-Dependent Toxic and Genotoxic Effects of Zinc Oxide Nanoparticles after Long-Term and Repetitive Exposure to Human Mesenchymal Stem Cells. Int. J. Environ. Res. Public Health 2017, 14, 1590. [CrossRef]

15. Tice, R.R.; Agurell, E.; Anderson, D.; Burlinson, B.; Hartmann, A.; Kobayashi, H.; Miyamae, Y.; Rojas, E.; Ryu, J.C.; Sasaki, Y.F. Single cell gel/comet assay: Guidelines for in vitro and in vivo genetic toxicology testing. Environ. Mol. Mutagen. 2000, 35, 206-221. [CrossRef]

16. Abdal Dayem, A.; Lee, S.B.; Cho, S.G. The Impact of Metallic Nanoparticles on Stem Cell Proliferation and Differentiation. Nanomaterials 2018, 8,761. [CrossRef]

17. Rejman, J.; Oberle, V.; Zuhorn, I.S.; Hoekstra, D. Size-dependent internalization of particles via the pathways of clathrin- and caveolae-mediated endocytosis. Biochem. J. 2004, 377, 159-169. [CrossRef]

18. Zuhorn, I.S.; Visser, W.H.; Bakowsky, U.; Engberts, J.B.; Hoekstra, D. Interference of serum with lipoplex-cell interaction: Modulation of intracellular processing. Biochim. Biophys. Acta 2002, 1560, 25-36. [CrossRef]

19. Win, K.Y.; Feng, S.S. Effects of particle size and surface coating on cellular uptake of polymeric nanoparticles for oral delivery of anticancer drugs. Biomaterials 2005, 26, 2713-2722. [CrossRef]

20. Hsiao, I.L.; Huang, Y.J. Effects of various physicochemical characteristics on the toxicities of $\mathrm{ZnO}$ and $\mathrm{TiO}$ nanoparticles toward human lung epithelial cells. Sci. Total Environ. 2011, 409, 1219-1228. [CrossRef]

21. Du, X.J.; Wang, J.L.; Iqbal, S.; Li, H.J.; Cao, Z.T.; Wang, Y.C.; Du, J.Z.; Wang, J. The effect of surface charge on oral absorption of polymeric nanoparticles. Biomater. Sci. 2018, 6, 642-650. [CrossRef] [PubMed]

22. Osaka, T.; Nakanishi, T.; Shanmugam, S.; Takahama, S.; Zhang, H. Effect of surface charge of magnetite nanoparticles on their internalization into breast cancer and umbilical vein endothelial cells. Colloids Surf. B Biointerfaces 2009, 71, 325-330. [CrossRef] [PubMed]

23. Massignani, M.; LoPresti, C.; Blanazs, A.; Madsen, J.; Armes, S.P.; Lewis, A.L.; Battaglia, G. Controlling cellular uptake by surface chemistry, size, and surface topology at the nanoscale. Small 2009, 5, 2424-2432. [CrossRef] [PubMed]

24. Hackenberg, S.; Scherzed, A.; Technau, A.; Froelich, K.; Hagen, R.; Kleinsasser, N. Functional responses of human adipose tissue-derived mesenchymal stem cells to metal oxide nanoparticles in vitro. J. Biomed. Nanotechnol. 2013, 9, 86-95. [CrossRef]

25. Chithrani, B.D.; Chan, W.C. Elucidating the mechanism of cellular uptake and removal of protein-coated gold nanoparticles of different sizes and shapes. Nano Lett. 2007, 7, 1542-1550. [CrossRef]

26. Bartczak, D.; Nitti, S.; Millar, T.M.; Kanaras, A.G. Exocytosis of peptide functionalized gold nanoparticles in endothelial cells. Nanoscale 2012, 4, 4470-4472. [CrossRef]

27. Panyam, J.; Labhasetwar, V. Dynamics of endocytosis and exocytosis of poly(D,L-lactide-co-glycolide) nanoparticles in vascular smooth muscle cells. Pharm. Res. 2003, 20, 212-220. [CrossRef]

(C) 2019 by the authors. Licensee MDPI, Basel, Switzerland. This article is an open access article distributed under the terms and conditions of the Creative Commons Attribution (CC BY) license (http://creativecommons.org/licenses/by/4.0/). 